\title{
Trajectories of Eating Behaviour Changes during Adolescence
}

\author{
Radhouene Doggui ${ }^{1, *}\left(\mathbb{C}\right.$, Stéphanie Ward ${ }^{2}\left[\right.$, Claire Johnson ${ }^{3}\left[\right.$ and Mathieu Bélanger ${ }^{1,4,5}$ \\ 1 Centre de Formation Médicale du Nouveau-Brunswick (Université de Sherbrooke), \\ Pavillon J.-Raymond-Frenette, Université de Moncton, 18 Antonine-Maillet Ave, \\ Moncton, NB E1A 3E9, Canada; mathieu.belanger@umoncton.ca \\ 2 École des Sciences des Aliments, de Nutrition et d'Études Familiales, Université de Moncton, \\ Moncton, NB E1A 3E9, Canada; stephanie.ward@umoncton.ca \\ 3 École des Hautes Études Publiques, Université de Moncton, Moncton, NB E1A 3E9, Canada; \\ claire.johnson@umoncton.ca \\ 4 Department of Family and Emergency Medicine, Université de Sherbrooke, Sherbrooke, QC J1K 2R1, Canada \\ 5 Vitalité Health Network, Moncton, NB E2A 1A9, Canada \\ * Correspondence: radhouene.doggui@usherbrooke.ca; Tel.: +1-506-863-2269
}

\section{check for}

updates

Citation: Doggui, R.; Ward, S.; Johnson, C.; Bélanger, M. Trajectories of Eating Behaviour Changes during Adolescence. Nutrients 2021, 13, 1313. https://doi.org/10.3390/nu13041313

Academic Editor: Emily Sonestedt

Received: 12 March 2021

Accepted: 14 April 2021

Published: 16 April 2021

Publisher's Note: MDPI stays neutral with regard to jurisdictional claims in published maps and institutional affiliations.

Copyright: (c) 2021 by the authors. Licensee MDPI, Basel, Switzerland. This article is an open access article distributed under the terms and conditions of the Creative Commons Attribution (CC BY) license (https:/ / creativecommons.org/licenses/by/ $4.0 /)$.

\begin{abstract}
Adolescence represents a critical transition phase during which individuals acquire eating behaviours that can track into adulthood. This study aims to characterise trends in eating behaviours throughout adolescence by investigating the presence of sub-groups of individuals presenting distinct trajectories of vegetable and fruit, sugary beverage, breakfast and fast-food consumption. Data from 744 MATCH study Canadian participants followed from 11 to 18 Years old (2013-2019) were included in the analyses. Participants reported how often they ate breakfast and consumed vegetables and fruits, sugary beverages and fast foods. Trajectories of eating behaviours over seven years were identified using group-based multi-trajectory modelling. For girls, three different groups were identified, namely 'stable food intake with a decline in daily breakfast consumption' (39.9\%), 'moderate food intake and worsening in overall eating behaviours' (38.0\%) and 'stable high food intake' (22.1\%). For boys, five different groups were identified, namely 'low food intake with stable daily breakfast consumption' (27.3\%), 'breakfast-skippers and increasing fast food intake' (27.1\%), 'low food intake with a decline in daily breakfast consumption' $(23.9 \%)$, 'high food intake with worsening of eating behaviours' (13.3\%) and 'average food intake with consistently high breakfast consumption' (8.4\%). Eating behaviours evolve through various distinct trajectories and sub-groupspecific strategies may be required to promote healthy eating behaviours among adolescents.
\end{abstract}

Keywords: adolescence; fruits and vegetables; sugary beverages; breakfast skipping; fast food; trajectory

\section{Introduction}

The transition from late childhood to adolescence is marked by significant eating behaviour changes [1]. Population-based studies have found that some eating behaviours, such as vegetable and fruit consumption, skipping breakfast [2], consuming sugary beverages [3] and eating fast foods [4], worsen as children enter adolescence. For example, a multi-national study conducted in the Eastern Mediterranean region showed a negative trend between age and the prevalence of eating vegetables and fruits $\geq 5$ times per day among adolescents [5]. Further, a national Canadian study found that while $98 \%$ of children 4-8 years old consumed breakfast daily this percentage decreased to $91 \%$ among 9-13-year-olds and 82\% among 14-18-year-olds [2]. Conversely, fast food consumption tends to increase during that same period. A longitudinal study in the United States found that fast food consumption increased from 2 times per week to 3 times per week between the ages of 11 and 18 [4]. Similarly, national data in the United States have shown that the prevalence of heavy sugary beverages consumption increased with age, where $5 \%$ of 
children as compared to $16 \%$ of adolescents consumed more than 500 calories from these beverages daily [3].

Findings from previous cross-sectional and longitudinal studies suggest that these eating behaviours are inter-dependant and may co-develop [6]. For example, studies have linked irregular breakfast consumption to lower intakes of vegetables and fruits among adolescents, and have shown that frequent fast food consumption is strongly correlated with skipping breakfast among this age group [7-9]. Fast food consumption has also been shown to be associated with a greater intake of sugary beverages [10]. However, for some behaviours, the relationship remains unclear. While one cross-sectional study among 15,283 Texan middle and high school students found that sugary beverages were associated with increased consumption of unhealthy foods (e.g., unhealthy meats, fried snacks, desserts), this study also found that soda intake was associated with lower consumption of vegetables and fruits, while flavoured and sports drinks were associated with a greater vegetable and fruit intake [11].

The emergence of group-based latent trajectory methods can be particularly interesting for advances in nutritional epidemiology research as it accounts for 'between-individual' variation when used to describe the continuity of different behaviours in a cohort of individuals over time. This addresses a limitation of previous longitudinal analyses, which described trends in dietary behaviours as a group average without acknowledging that sub-groups of individuals may present development patterns that vary from the group average. In particular, population-based trajectory models do not consider clusters of individuals who follow similar eating behaviour trajectories and who could be at a greater health risk than others [12]. Few studies have considered between-individual variation and the potential that different groups of individuals follow distinct developmental trajectories for different behaviours [6,13]. For example, the recent use of group-based latent class analyses has helped identify important differences in how sub-groups of individuals follow distinct trends regarding adherence to the Mediterranean diet [14], traditional or modern diets in China. Further, a study by Chen and Hsiao [6] identified two heterogeneous eating behaviour trajectories among girls and two among boys between the ages of 9 and 13. Specifically, this Taiwanese study found that one group of girls was characterised by consistent daily consumption of breakfast with a shift from high to low vegetable and fruit intake while a second group presented irregular breakfast consumption and low vegetable and fruit intake. Among boys, one group was characterised by having a consistent daily consumption of breakfast and a high intake of vegetables and fruits, while the second group presented irregular breakfast consumption and a low intake of vegetables and fruits. These studies highlight the importance of considering the potential for various trajectories when describing the development of eating behaviours. Moreover, these studies call for a better understanding of the co-development of different eating behaviours among boys and girls during adolescence. Information on multi-behaviour co-development could help identify intervention requirements specific to adolescent sub-groups.

This study aimed to investigate the presence of naturally occurring sub-groups of girls and boys following distinct trajectories of multiple eating behaviours (i.e., daily breakfast consumption, fast food consumption, vegetable and fruit intake, and sugary beverage intake). We hypothesised that several different patterns of development of eating behaviours would be identified; at least a group with a worsening of the majority of eating behaviours and another group with a healthy profile for the development of eating behaviours. Finally, we expected to find that an improvement in one eating behaviour would correlate with the improvements in other eating behaviours.

\section{Methods}

\subsection{Study Population}

This study used data collected from 937 children (mean age 10.8 years old, in Grades 5 and 6 at study inception) recruited from 17 elementary schools in New Brunswick, Canada for the Monitoring Activities for Teenagers to Comprehend their Habits (MATCH) 
longitudinal study [15]. Detailed information on the MATCH study protocol has been published elsewhere [15], but briefly, students completed a self-reported questionnaire three times per academic year, over 8 years from 2011 to 2019. They came from schools selected to represent geographical (i.e., rural and urban), and cultural (i.e., French and English) diversity. Questions related to students' eating behaviours were included once per academic year, starting in the second year of data collection. Therefore, seven cycles (cycles 5, 8, 11, 14, 17, 20 and 23) of data were available for analysis.

\subsection{Eating Behaviours}

For this study, eating behaviours included daily breakfast consumption, fast food consumption, vegetable and fruit intake, and sugary beverage intake. For breakfast and fast food consumption, participants were asked to identify the number of days (0 to 7) over the course of the previous week they had eaten breakfast and had eaten a meal or snack at a fast food restaurant. Participants were then categorised as daily breakfast eaters (i.e., eating breakfast seven times during the previous week) or not [16]. Vegetable and fruit intake was assessed by asking 'How many times in the past 7 days have you eaten ... ', followed by 5 food items (i.e., fruit, salad, potatoes, carrots, other vegetables). Similarly, participants were asked 'How many times in the past 7 days have you drank ... ', followed by 9 beverage items (i.e., fruit juice, soft drinks, diet soft drinks, sports drinks, energy drinks, coffee/tea or other coffee-flavoured products, sugar-sweetened beverages, water and milk). For these items, response options included: 'I did not eat (drink) this in the past 7 days', ' 1 to 3 times in the past 7 days', ' 4 to 6 times in the past 7 days', ' 1 time per day', ' 2 times per day', ' 3 times per day' and ' 4 times per day or more' [17,18]. The questionnaire showed good test-retest reliability (kappa $\geq 0.61$ ) over two weeks [19]. All responses were converted to daily frequency equivalents. For response options with a range, the middle value of the interval was used in analyses such that ' 1 to 3 times in the past 7 days' was represented as 0.29 times per day, ' 4 to 6 times in the past 7 days' was transformed to 0.71 times per day, and ' 4 times per day or more' was expressed as 4 times per day. Vegetable and fruit intake was determined by calculating the sum of the frequency of intake of all items in this category. Sugary beverage intake represented the sum of all beverages with the exclusion of coffee and tea, water and milk.

\subsection{Data Analysis}

\subsubsection{Descriptive Analysis}

For both genders, median frequency change over time for vegetable and fruit intake, daily breakfast consumption and fast food consumption was assessed by fixed effect quantile regression [20]. Fixed-effect Poisson regression [21] was used to evaluate the frequency of sugary beverage intake over time. The age of participants was used as the time variable and was introduced as a categorical independent variable. The assessment of linear and quadratic trends was done by orthogonal polynomial contrasts.

\subsubsection{Group Based Multi-Trajectory Modelling}

The group-based multi-trajectory group modelling approach developed by Nagin et al. [22] was used to assess the co-development of the eating behaviours (Traj command in Stata 16.1 (Stata Corporation, College Station, TX, USA, 2019), [23,24]). This approach is based on the application of finite-mixture models which assume that a population is composed of a mixture of distinct groups that could be differentiated by their distinct trajectories of behaviour development [12]. Participants who had complete data on at least two measurement points were retained for this analysis. Given that the ShapiroWilk test pointed to a non-normal distribution of the 'vegetable and fruit intake ', 'sugary beverage intake' and 'fast food consumption' variables, these variables were modelled by a beta distribution as recommended by Elmer et al. [25]. The 'daily breakfast consumption' variable was expressed as the probability of adherence to the recommendation of having breakfast every day (7 days a week) and modelled as a logit distribution. Group-based 
multi-trajectory group modelling was conducted separately for girls and boys [26]. The optimal number of groups was based on the best-fitting model using the Bayesian Information Criterion. Then, various polynomial functions were tested for each latent trajectory class to determine if they should be modelled as linear, quadratic or cubic patterns of change throughout adolescence. Before retaining a model, we verified that the requirements of minimum mean posterior probability of group was $\geq 70 \%$, odds of correct classification $\geq 5$ and that each group included $\geq 5 \%$ of participants in the sample. Following the identification of the trajectory groups, a label was assigned to each group to characterise their pattern of overall eating behaviours. Finally, in the interest of parsimony, the models presented do not include adjustments for culture (francophone or anglophone) or geographical location (rural or urban) since preliminary analyses indicated these variables provided no additional meaningful information.

\section{Results}

\subsection{Description of the Study Sample}

Of the 937 participants recruited in the MATCH study, 744 provided data during at least two of the survey cycles when questions on eating behaviours were administered and were therefore retained for these analyses. Of these participants, $44.2 \%$ were boys, $52.4 \%$ attended a school in a rural area, and two-thirds attended a Francophone school.

\subsection{Average Eating Behaviour Trends}

Among girls, the median (Table 1) frequency of vegetable and fruit intake, sugary beverage intake and daily breakfast consumption were characterised by a marked linear decline throughout adolescence. Boys also reported a linear decline in daily breakfast consumption over time whereas their sugary beverage intake increased in early adolescence before dropping to lower levels by the end of follow-up. 
Table 1. Median frequencies of eating behaviours from childhood to adolescence.

\begin{tabular}{|c|c|c|c|c|c|c|c|c|c|c|c|c|c|c|c|c|c|c|}
\hline \multirow{2}{*}{$\begin{array}{c}\text { Eating } \\
\text { Behaviours }\end{array}$} & \multicolumn{2}{|c|}{$\begin{array}{l}11 \text { Years } \\
(n=309)\end{array}$} & \multicolumn{2}{|c|}{$\begin{array}{l}12 \text { Years } \\
(n=587)\end{array}$} & \multicolumn{2}{|c|}{$\begin{array}{l}13 \text { Years } \\
(n=579)\end{array}$} & \multicolumn{2}{|c|}{$\begin{array}{l}14 \text { Years } \\
(n=497)\end{array}$} & \multicolumn{2}{|c|}{$\begin{array}{l}15 \text { Years } \\
(n=445)\end{array}$} & \multicolumn{2}{|c|}{$\begin{array}{l}16 \text { Years } \\
(n=419)\end{array}$} & \multicolumn{2}{|c|}{$\begin{array}{l}17 \text { Years } \\
(n=347)\end{array}$} & \multicolumn{2}{|c|}{$\begin{array}{c}18 \text { Years } \\
(n=47)\end{array}$} & \multicolumn{2}{|c|}{$P$ Trend } \\
\hline & Median & $\mathrm{IQR}^{1}$ & Median & $\mathrm{IQR}^{1}$ & Median & IQR $^{1}$ & Median & $\mathrm{IQR}^{1}$ & Median & $\mathrm{IQR}^{1}$ & Median & $\mathrm{IQR}^{1}$ & Median & $\mathrm{IQR}^{1}$ & Median & $\mathrm{IQR}^{1}$ & Linear & Quadratic \\
\hline \multicolumn{19}{|c|}{ Overall $(n=744)$} \\
\hline $\begin{array}{l}\text { beverage } \\
\text { (daily) }\end{array}$ & 2.0 & $1.0-4.3$ & 1.7 & $0.9-4.0$ & 1.9 & $0.9-4.0$ & 1.3 & $0.6-4.0$ & 1.3 & $0.3-3.6$ & 1.3 & $0.3-3.3$ & 1.09 & $0.3-2.1$ & 0.6 & $0.0-2.0$ & $<0.0001$ & $<0.0001$ \\
\hline $\begin{array}{c}\text { Breakfast } \\
\text { (Daily) }\end{array}$ & 7.0 & $5.0-7.0$ & 7.0 & $5.0-7.0$ & 7.0 & $4.0-7.0$ & 7.0 & $4.0-7.0$ & 7.0 & $4.0-7.0$ & 7.0 & $4.0-7.0$ & 6.0 & $4.0-7.0$ & 6.0 & $3.0-7.0$ & $<0.0001$ & 0.56 \\
\hline $\begin{array}{l}\text { Fast food } \\
\text { (Daily) }\end{array}$ & 1.0 & $0.0-1.0$ & 1.0 & $0.0-1.0$ & 1.0 & $0.0-1.0$ & 1.0 & $0.0-2.0$ & 1.0 & $0.0-2.0$ & 1.0 & $0.0-2.0$ & 1.0 & $0.0-2.0$ & 1.0 & $0.0-2.0$ & $<0.0001$ & 0.96 \\
\hline \multicolumn{19}{|c|}{ Girls $(n=415)$} \\
\hline $\begin{array}{c}\text { Vegetable and } \\
\text { fruit (daily) } \\
\text { Sugary }\end{array}$ & 4.7 & $2.3-6.7$ & 4.3 & $2.3-7.0$ & 4.1 & $2.1-6.5$ & 4.1 & $2.1-6.3$ & 4.1 & $2.7-6.6$ & 4.0 & $2.3-6.4$ & 3.9 & $1.7-5.7$ & 4.0 & $1.9-6.0$ & $<0.0001$ & 0.49 \\
\hline $\begin{array}{l}\text { beverage } \\
\text { (daily) }\end{array}$ & 1.7 & $1.0-4.0$ & 1.3 & $0.7-3.6$ & 1.3 & $0.7-3.0$ & 1.0 & $0.3-2.1$ & 1.0 & $0.3-2.6$ & 1.0 & $0.3-1.9$ & 0.7 & $0.3-1.3$ & 0.4 & $0.0-1.0$ & $<0.0001$ & 0.034 \\
\hline $\begin{array}{c}\text { Breakfast } \\
\text { (Daily) }\end{array}$ & 7.0 & $5-7$ & 7.0 & $4.0-7.0$ & 6.0 & $3.0-7.0$ & 7.0 & $4.0-7.0$ & 7.0 & $4.0-7.0$ & 7.0 & $4.0-7.0$ & 6.0 & $4.0-7.0$ & 5.5 & $3.0-7.0$ & 0.042 & 0.39 \\
\hline $\begin{array}{l}\text { Fast food } \\
\text { (Daily) }\end{array}$ & 1.0 & $0.0-1.0$ & 1.0 & $0.0-1.0$ & 0.0 & $0.0-1.0$ & 1.0 & $0.0-2.0$ & 1.0 & $0.0-2.0$ & 1.0 & $0.0-2.0$ & 1.0 & $0.0-2.0$ & 1.0 & $0.0-1.0$ & 0.12 & 0.72 \\
\hline $\begin{array}{c}\text { Vegetable and } \\
\text { fruit (daily) } \\
\text { Sugary }\end{array}$ & 3.9 & $2.1-6.7$ & 4.7 & $2.1-7.7$ & 4.4 & $1.9-7.3$ & 4.0 & $2.0-7.0$ & 4.0 & $1.6-7.0$ & 3.3 & $1.4-6.6$ & 3.0 & $1.4-5.4$ & 3.0 & $1.3-6.0$ & 0.41 & 0.83 \\
\hline $\begin{array}{l}\text { beverage } \\
\text { (daily) }\end{array}$ & 2.1 & $1.0-4.9$ & 2.3 & $1.0-4.7$ & 3.0 & $1.0-6.0$ & 2.5 & $1.0-5.4$ & 2.1 & $0.7-4.3$ & 2.1 & $1.0-4.9$ & 1.6 & $0.3-3.3$ & 1.0 & $0.3-2.4$ & $<0.0001$ & $<0.0001$ \\
\hline $\begin{array}{c}\text { Breakfast } \\
\text { (Daily) }\end{array}$ & 7.0 & $6.0-7.0$ & 7.0 & $6.0-7.0$ & 7.0 & $5.0-7.0$ & 7.0 & $4.0-7.0$ & 7.0 & $4.0-7.0$ & 7.0 & $4.0-7.0$ & 6.0 & $4.0-7.0$ & 5.5 & $2.5-7.0$ & $<0.0001$ & 0.47 \\
\hline $\begin{array}{c}\text { Fast food } \\
\text { (Daily) }\end{array}$ & 1.0 & $0-1.0$ & 0.0 & $0.0-1.0$ & 1.0 & $0.0-1.0$ & 1.0 & $0.0-2.0$ & 1.0 & $0.0-3.0$ & 1.0 & $0.0-3.0$ & 2.0 & $0.0-3.0$ & 1.5 & $0.0-3.0$ & 0.39 & 0.94 \\
\hline
\end{tabular}

${ }^{1}$ Interquartile range. 


\subsection{Eating Behaviour Trajectories}

Three groups were identified to present distinct trajectories of multiple eating behaviours among girls, whereas five groups emerged among boys (Table 2). No group emerged as presenting consistent healthy eating behaviours among girls or boys. The largest group among girls included $40 \%$ of participants and was labelled 'stable low food intake with a decline in daily breakfast consumption' as it was characterised by a very low intake of vegetables and fruits, sugary beverages and fast food (Figure 1). Adherence to the recommendation to consume breakfast daily declined consistently within this group. The second group contained nearly as many participants (38\%) and was labelled 'moderate food intake and worsening of overall eating behaviours' given it showed a significant decrease in vegetable and fruit intake, sugary beverage intake and daily breakfast consumption. The 3 rd group displayed the lowest proportion (22.1\%) of girls and was labelled 'stable high food intake'. Girls belonging to this group showed stable and relatively high frequencies for all eating behaviours.

Table 2. The estimated group-specific trajectory regression coefficients for the group-based multi-trajectory model $(n=744)$.

\begin{tabular}{|c|c|c|c|c|c|c|c|c|c|c|}
\hline \multirow{2}{*}{ Group } & \multirow[b]{2}{*}{$\%$} & \multirow[b]{2}{*}{ Term } & \multicolumn{2}{|c|}{ Vegetables and Fruits } & \multicolumn{2}{|c|}{ Sugary Beverages } & \multicolumn{2}{|c|}{ Breakfast } & \multicolumn{2}{|c|}{ Fast Food } \\
\hline & & & Estimate \pm s.e. ${ }^{1}$ & $\begin{array}{c}p \\
\text { Value }\end{array}$ & Estimate \pm s.e. & $\begin{array}{c}p \\
\text { Value }\end{array}$ & Estimate \pm s.e. & $\begin{array}{c}p \\
\text { Value }\end{array}$ & Estimate \pm s.e. & $p$ Value \\
\hline & & \multicolumn{9}{|c|}{ Girls $(n=415)$} \\
\hline $\begin{array}{l}1 \\
2 \\
3\end{array}$ & $\begin{array}{l}39.9 \\
38.0 \\
22.1\end{array}$ & $\begin{array}{l}\text { Intercept } \\
\text { Linear } \\
\text { Intercept } \\
\text { Linear } \\
\text { Intercept } \\
\text { Linear } \\
\text { Quadratic }\end{array}$ & $\begin{array}{c}-2.00 \pm 0.20 \\
0.02 \pm 0.01 \\
0.09 \pm 0.24 \\
-0.06 \pm 0.02 \\
-3.42 \pm 3.62 \\
0.46 \pm 0.52 \\
-0.02 \pm 0.02\end{array}$ & $\begin{array}{c}<0.0001 \\
0.27 \\
0.71 \\
0.0002 \\
0.34 \\
0.37 \\
0.36 \\
\end{array}$ & $\begin{array}{c}-1.50 \pm 0.25 \\
-0.10 \pm 0.02 \\
-0.53 \pm 0.27 \\
-0.14 \pm 0.02 \\
-5.70 \pm 3.29 \\
0.72 \pm 0.47 \\
-0.02 \pm 0.02\end{array}$ & $\begin{array}{l}<0.0001 \\
<0.0001 \\
0.050 \\
<0.0001 \\
0.083 \\
0.12 \\
0.099 \\
\end{array}$ & $\begin{array}{c}1.01 \pm 0.61 \\
-0.09 \pm 0.04 \\
2.26 \pm 0.68 \\
-0.11 \pm 0.05 \\
6.36 \pm 5.98 \\
-0.93 \pm 0.85 \\
0.03 \pm 0.03\end{array}$ & $\begin{array}{c}0.063 \\
0.026 \\
0.0009 \\
0.017 \\
0.36 \\
0.35 \\
0.35\end{array}$ & $\begin{array}{c}-2.16 \pm 0.32 \\
0.03 \pm 0.02 \\
-3.02 \pm 0.31 \\
0.05 \pm 0.02 \\
-9.18 \pm 3.67 \\
1.13 \pm 0.53 \\
-0.04 \pm 0.02\end{array}$ & $\begin{array}{c}<0.0001 \\
0.15 \\
<0.0001 \\
0.036 \\
0.012 \\
0.032 \\
0.047\end{array}$ \\
\hline \multicolumn{11}{|c|}{ Model goodness of fit } \\
\hline & $\begin{array}{l}(N= \\
(N= \\
\text { AIC } \\
\text {-likeli }\end{array}$ & $\begin{array}{l}\text { 92) } \\
\text { 15) } \\
\text { od }\end{array}$ & $\begin{array}{l}5116.7 \\
5172.3 \\
5250.8 \\
5289.8\end{array}$ & & & & & & & \\
\hline & & \multicolumn{9}{|c|}{ Boys $(n=329)$} \\
\hline 1 & 23.9 & $\begin{array}{l}\text { Intercept } \\
\text { Linear } \\
\text { Quadratic }\end{array}$ & $\begin{array}{c}-2.12 \pm 0.09 \\
- \\
-\end{array}$ & $\begin{array}{l}<0.0001 \\
- \\
-\end{array}$ & $\begin{array}{c}-1.91 \pm 0.41 \\
-0.04 \pm 0.03 \\
-\end{array}$ & $\begin{array}{l}<0.0001 \\
0.11 \\
-\end{array}$ & $\begin{array}{c}5.66 \pm 1.19 \\
-0.38 \pm 0.08 \\
-\end{array}$ & $\begin{array}{l}<0.0001 \\
<0.0001 \\
-\end{array}$ & $\begin{array}{c}6.48 \pm 3.78 \\
-1.27 \pm 0.54 \\
0.04 \pm 0.02\end{array}$ & $\begin{array}{l}0.086 \\
0.018 \\
0.012\end{array}$ \\
\hline 2 & 27.3 & $\begin{array}{l}\text { Intercept } \\
\text { Linear } \\
\text { Ouadratic }\end{array}$ & $\begin{array}{c}-0.49 \pm 0.28 \\
-0.03 \pm 0.02 \\
-\end{array}$ & $\begin{array}{l}0.078 \\
0.072 \\
-\end{array}$ & $\begin{array}{c}-1.15 \pm 0.37 \\
-0.08 \pm 0.027\end{array}$ & $\begin{array}{c}0.0021 \\
0.0016 \\
-\end{array}$ & $\begin{array}{c}6.10 \pm 1.54 \\
-0.29 \pm 0.10 \\
-\end{array}$ & $\begin{array}{l}0.0001 \\
0.0037 \\
-\end{array}$ & $\begin{array}{c}2.32 \pm 3.25 \\
-0.73 \pm 0.46 \\
0.03 \pm 0.02\end{array}$ & $\begin{array}{l}0.47 \\
0.11 \\
0.082\end{array}$ \\
\hline 3 & 8.4 & $\begin{array}{l}\text { Quadratic } \\
\text { Intercept } \\
\text { Linear }\end{array}$ & $\begin{array}{c}1.94 \pm 0.87 \\
-0.59 \pm 0.05\end{array}$ & $\begin{array}{l}0.025 \\
0.025\end{array}$ & $\begin{array}{c}0.06 \pm 0.64 \\
-0.11 \pm 0.04\end{array}$ & $\begin{array}{c}0 . \overline{-} \\
0.013 \\
-\end{array}$ & $\begin{aligned} & 1.66 \pm \\
& \pm \\
&- 0.34 \\
&-\end{aligned}$ & $\begin{array}{l}<0.0001 \\
- \\
-\end{array}$ & $\begin{array}{c}-2.37 \pm 0.83 \\
0.07 \pm 0.05 \\
-\end{array}$ & $\begin{array}{c}0.0043 \\
0.19 \\
-\end{array}$ \\
\hline 4 & 13.3 & Intercept & $\begin{array}{c}1.62 \pm 0.08 \\
-0.11 \pm 0.06\end{array}$ & $\begin{array}{l}0.051 \\
0.046\end{array}$ & $\begin{array}{c}0.04 \pm 0.77 \\
-0.06 \pm 0.05\end{array}$ & $\begin{array}{l}0.61 \\
0.30\end{array}$ & $\begin{array}{c}5.71 \pm 1.41 \\
-0.43 \pm 0.10\end{array}$ & $\begin{array}{l}0.0001 \\
<0.0001\end{array}$ & $\begin{array}{c}-2.91 \pm 0.79 \\
0.17 \pm 0.05\end{array}$ & $\begin{array}{l}0.0003 \\
0.0018\end{array}$ \\
\hline 5 & 27.1 & $\begin{array}{l}\text { Quadratic } \\
\text { Intercept } \\
\text { Linear } \\
\text { Quadratic }\end{array}$ & $\begin{array}{c}- \\
-6.36 \pm 3.22 \\
0.82 \pm 0.46 \\
-0.03 \pm 0.01\end{array}$ & $\begin{array}{l}-\overline{0} \\
0.048 \\
0.077 \\
0.060\end{array}$ & $\begin{array}{c}-10.5 \overline{6} \pm 3.25 \\
1.38 \pm 0.46 \\
-0.050 \pm 0.016\end{array}$ & $\begin{array}{l}-\overline{-} \\
0.0012 \\
0.0030 \\
0.0020\end{array}$ & $\begin{array}{c}- \\
-3.21 \pm 7.89 \\
0.55 \pm 1.13 \\
-0.02 \pm 0.04\end{array}$ & $\begin{array}{l}- \\
0.68 \\
0.62 \\
0.53\end{array}$ & $\begin{array}{c}- \\
-3.57 \pm 0.60 \\
0.20 \pm 0.04 \\
-\end{array}$ & $\begin{array}{l}<0 . \overline{0} \\
<0.0001 \\
-\end{array}$ \\
\hline \multicolumn{11}{|c|}{ Model goodness of fit } \\
\hline $\mathrm{BI}$ & $\begin{array}{l}2(N= \\
C(N= \\
\text { AIC } \\
\text {-likeli }\end{array}$ & $\begin{array}{l}\text { 301) } \\
\text { 29) } \\
\text { ood }\end{array}$ & $\begin{array}{l}2921.1 \\
3007.9 \\
3125.5 \\
3187.5\end{array}$ & & & & & & & \\
\hline
\end{tabular}

\footnotetext{
${ }^{1}$ Standard error. ${ }^{2}$ Bayesian information criterion. ${ }^{3}$ Akaike information criterion.
} 

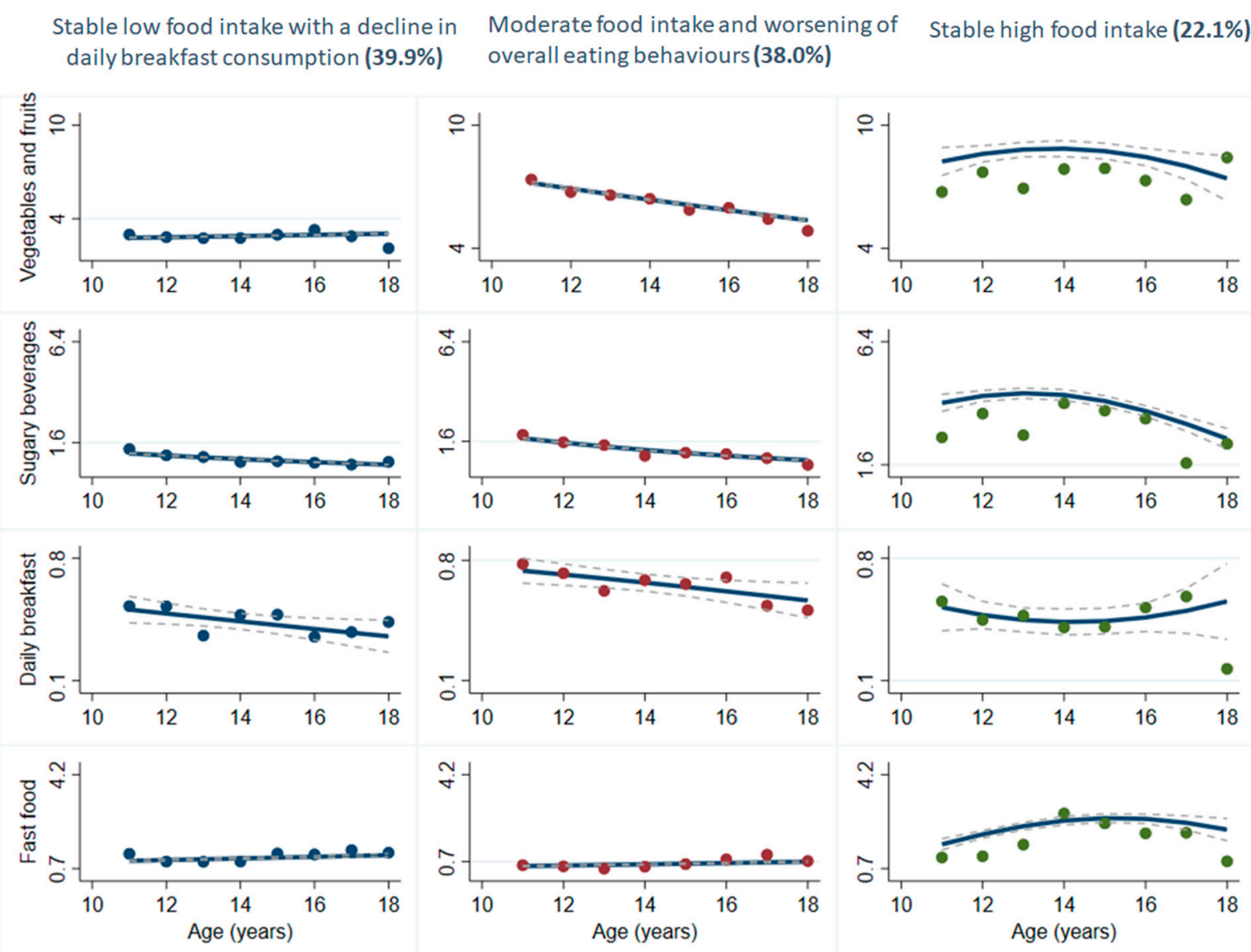

Figure 1. Multi-trajectory modelling of four eating behaviours among adolescent girls in the MATCH study. Figure caption: MATCH: Monitoring Activities of Teenagers to Comprehend their Habits. A dashed line represents the $95 \%$ confidence interval. Solid lines represent the average frequency of daily intakes for vegetables and fruits, sugary beverages and fast food, and the probability of daily breakfast consumption.

Among boys, the largest group included 27.3\% of participants and was labelled 'Low food intake with stable daily breakfast consumption'. Participants in this group had a low vegetable and fruit intake and low fast food consumption throughout follow-up (Figure 2). This group was also characterised by a low and declining intake of sugary beverages and a high, but declining adherence to daily breakfast consumption. A second group also represented $27.1 \%$ of participants and was labelled 'breakfast-skippers and increasing fast food intake'. It included boys with the lowest probability of eating breakfast daily. Boys belonging to this group also presented a substantial increase in fast food consumption and a consistently low intake of vegetables and fruits. A group including $24 \%$ of boys was labelled 'low food intake with a decline in daily breakfast consumption' showed stable and low intakes of vegetables, fruits and sugary beverages. This group also had a sharp decline in daily breakfast consumption. The 'high food intake with worsening of eating behaviours' group included $13 \%$ of participants and showed a relatively high intake of sugary beverages, an increase in fast food consumption and a decline in vegetable and fruit intake. The smallest group of boys ( $8 \%$ of participants) was labelled 'average food intake with consistently high breakfast consumption'. This group showed high and consistent daily breakfast consumption but was otherwise similar to other groups with regards to the other eating behaviours. 
Low food intake with a decline in daily breakfast consumption (23.9\%)
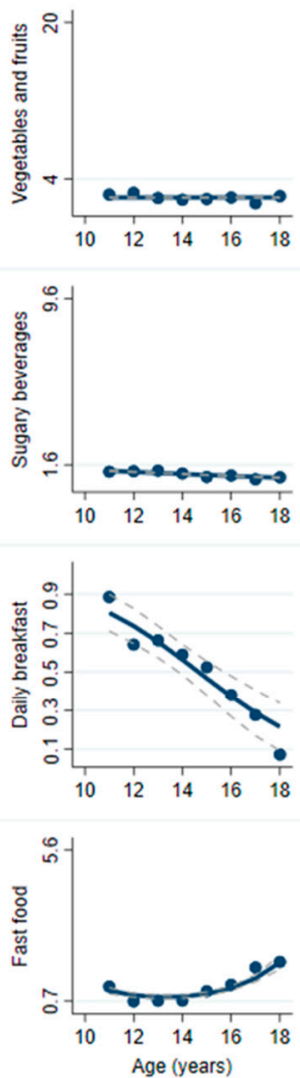

Low food intake with stable daily breakfast consumption (27.3\%)
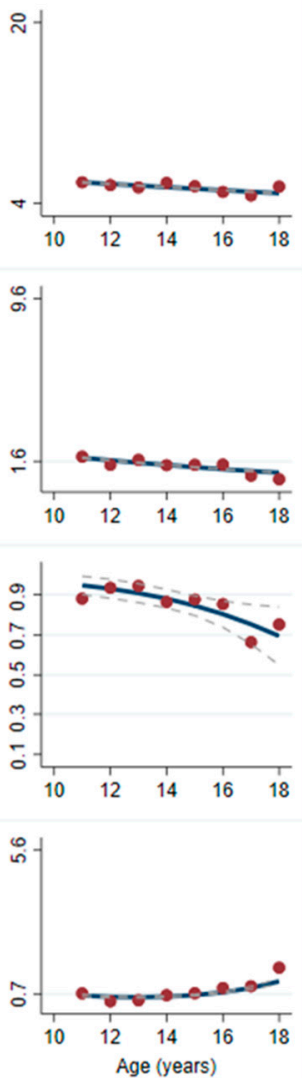

Average food intake with consistently high breakfast consumption (8.4\%)
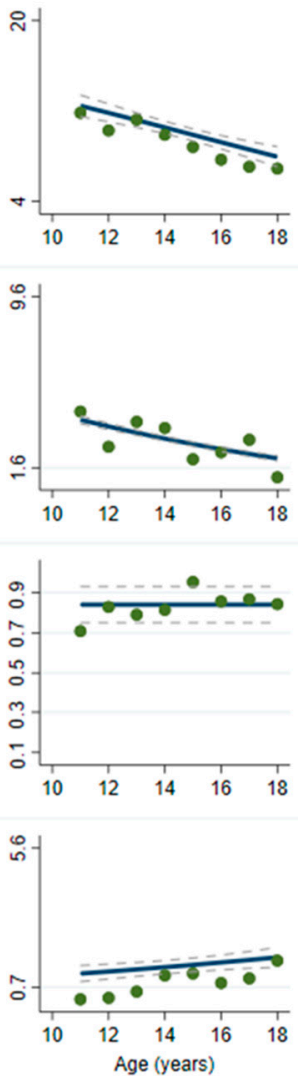

High food intake with worsening of eating behaviours (13.3\%)
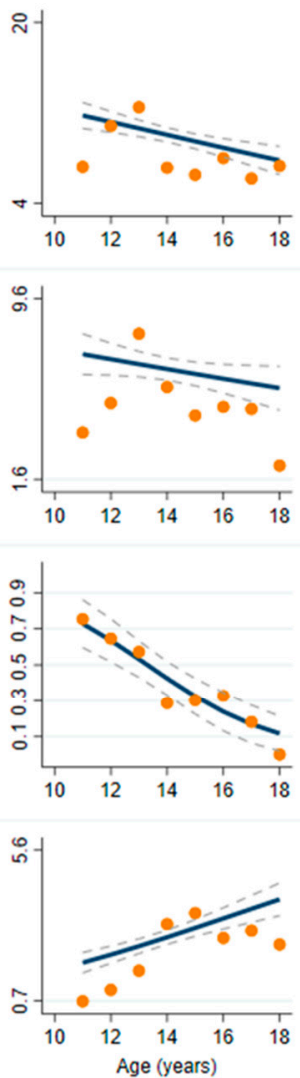
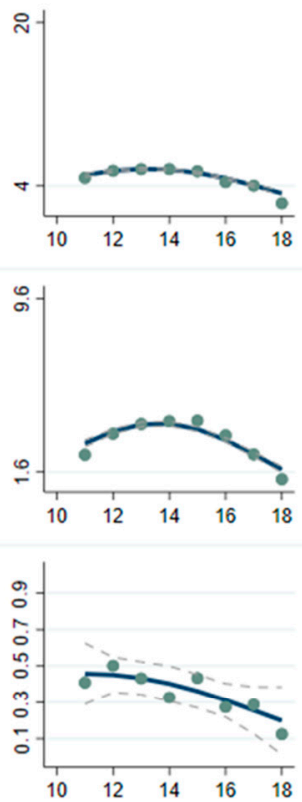

Breakfast skippers and increasing fast food intake (27.1\%)

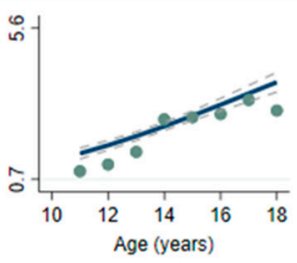

Figure 2. Multi-trajectory modelling of four eating behaviours among adolescent boys in the MATCH study. Figure caption: MATCH: Monitoring Activities of Teenagers to Comprehend their Habits. Dashed line represents the $95 \%$ confidence interval. Solid lines represent the average frequency of daily intakes for vegetables and fruits, sugary beverages and fast food, and the probability of daily breakfast consumption.

\section{Discussion}

\subsection{Key Findings}

This study is the first to use multi-trajectory groups to illustrate how four common eating behaviours evolve throughout adolescence. Our study found a total of eight different eating behaviour group trajectories; three among girls and five among boys. None of the groups demonstrated consistent healthy eating behaviours. Among both genders, average trends showed a worsening of most eating behaviours, with declines in daily breakfast consumption emerging in almost every group. Our findings also showed that while some eating behaviours may improve in some adolescents, this does not necessarily translate to improvements in other eating behaviours. These findings not only demonstrate the need for nutrition interventions in adolescence, but also the diversity and complexity of eating behaviour development among this age group.

\subsection{Breakfast and Fast Food Trajectories}

Of the four eating behaviours assessed, daily breakfast consumption appears to be the most unstable as it declined in six of the eight trajectory groups identified. Other Canadian studies also found low adherence to daily breakfast recommendations among adolescents. In one study, $48.5 \%$ of Canadian adolescents were found to skip breakfast at least once a 
week [27] and another study reported a general decline in breakfast consumption with age during adolescence [2]. Adolescents may therefore be missing out on the many nutritional and health benefits of regular breakfast consumption $[4,28,29]$. In particular, skipping breakfast has been linked to increased feelings of hunger [30], which may lead to greater consumption of high-energy foods [31]. This may partly explain why our study found that for three of the sub-groups among boys (64.3\%), a decline in breakfast consumption coincided with an increase in fast food consumption. In addition to being of low nutritional quality, fast foods are typically considered ultra-processed foods, which have been linked to overconsumption, increased caloric intake and ultimately, weight gain [32]. The common co-development of these two behaviours (skipping breakfast and fast food consumption) raises concern not only because of their effect on weight [4] but also because of their potential compounding effect on short and long-term health outcomes (e.g., obesity) [33]. It may therefore be strategic to develop interventions targeting both regular breakfast consumption and low fast food intake simultaneously among adolescent boys.

\subsection{Vegetables and Fruits Trajectory}

In general, girls reported higher intakes of vegetables and fruits than boys. Nevertheless, four out of eight groups displayed consistently low intakes of vegetables and fruits and three other groups showed a steep decline in vegetable and fruit consumption during adolescence. Our findings are consistent with previous cross-sectional studies that showed that Canadian adolescents generally consume insufficient amounts of vegetables and fruits [34] and that this behaviour seems to worsen as adolescents become older [35]. Only one group among girls met the recommended intake for vegetables and fruits, which aligns with findings from previous studies $[34,36]$. For example, an international crosssectional study showed that fruit consumption was more common among Canadian girls compared to boys in early and mid-adolescence [36]. However, this contrasts with a 2004 to 2015 trend analysis reporting a higher frequency of vegetable and fruit intake among boys ( 2.96 to 2.40 servings per day) than girls (2.5 to 1.93 servings per day) [37]. Considering the importance of vegetables and fruits for adolescents' optimal growth, development and overall health, our findings highlight the importance of continuing to promote the consumption of these foods to the majority of adolescents.

\subsection{Sugary Beverages Trajectory}

In contrast with other eating behaviours, we noted an improvement in the majority of groups (six of eight) concerning the consumption of sugary beverages. The decline in sugary beverages observed in our sample may reflect a trend observed throughout Canada, where sugary beverage intake was found to drop from 2004 to 2015 [38,39]. Although trends characterizing sugary beverage intake are improving, these beverages remain a concerning source of sugar and total energy intake in Canadian children and adolescents [39]. Our results also align with the recent national data showing that sugars represent nearly onequarter of Canadian adolescents' daily energy intake [39], which is more than double the $5-10 \%$ recommended by the World Health Organization [40]. Considering the short and long-term health consequences of high sugar intakes [41], public health messaging should therefore continue to encourage adolescents to decrease their intake of sugars, particularly from beverages.

\subsection{Public Health Significance}

While this study demonstrates changes in eating behaviours during adolescence, it is difficult to establish a specific time point or age when these changes occur. However, changes in eating behaviours often correspond with the transition from middle school to high school, where adolescents have more autonomy regarding their food choices and eating behaviours [42]. Adolescence is also typically a time when concerns regarding body image emerge, which can lead to unhealthy eating behaviours such as reducing food intake and skipping meals in an effort to lose weight [43]. In fact, one Canadian study found that 
$58 \%$ of adolescent girls reported 'trying to lose weight' as their weight goal [43]. This could help explain why declines in sugary beverages, daily breakfast, as well as vegetables and fruits, were observed in a greater proportion of girls than boys sub-groups in our study. Considerations such as these, and gender-specific findings in this study, highlight the need for gender-specific approaches during adolescence as has been suggested previously [44].

Further, the identification of different groups among boys and girls, and the observation that each group presents at least one unhealthy eating behaviour trajectory, underscores the complexity of addressing adolescents' eating behaviours from a population perspective. Contrary to expectations, improvements in one eating behaviour did not necessarily correlate with improvements in other eating behaviours. As such, it is unlikely that simple public health messages (i.e., consuming more vegetables and fruits or eating breakfast daily) would be sufficient to improve adolescents' overall diet. Considering the heterogeneity in eating behaviours of adolescents, it may be necessary to address various eating behaviours simultaneously. Coupling general public health messages with more targeted interventions may be required to address the co-development of multiple eating behaviours during adolescence. Public health authorities are urged to intervene as early as possible, namely during childhood or early adolescence to prevent the worsening of eating behaviours. Additionally, there is evidence that gender-specific interventions may be needed to improve adolescents' nutrition. Since gender differences in eating behaviour trajectories might be explained by differences in girls' and boys' perception of what constitutes a healthy diet [45], public health initiatives should focus on improving nutrition knowledge while also addressing adolescents' perceived barriers to healthy eating.

Previous studies suggested that eating behaviours track from adolescence to early adulthood [46]. While this study did not assess behaviours in adulthood, results suggest that during adolescence, eating behaviours can track in some individuals but not all. Future analyses should investigate which adolescents' eating behaviours track in adulthood. Future studies should also seek to identify determinants of the various eating behaviour trajectory classes. Additional information on characteristics associated with the various groups will help inform public health interventions.

\subsection{Strengths and Limitations}

The present study had several strengths, including the relatively large sample and the inclusion of multiple measures over seven years spanning the transition from late childhood through adolescence. In addition, this study moved away from presenting general trends for the entire sample. Further, it accounted for the co-development of four common eating behaviours, which provides a greater understanding of the complexity of eating behaviour development throughout adolescence.

Our study also has some limitations. First, since participants reported how many times they consumed a food rather than the number of servings, is not possible to know if answers provided corresponded with standard serving sizes, nor did it provide information on daily caloric intake. Second, the use of a self-report questionnaire may have resulted in under- or over-reporting due to recall and social desirability biases [47]. Third, while this study did consider four important eating behaviours of adolescents, it did not consider all of them (e.g., snacking/grazing, distractive eating, dieting, etc.).). Finally, the sampling design of this study does not allow for generalisations among all adolescents.

\section{Conclusions}

This study allowed identifying multiple patterns of eating behaviour development throughout adolescence. These patterns are generally characterised by a worsening of eating behaviours during adolescence, except for sugary beverage intake, which stabilised or decreased over the seven years of the study. Further highlighting the complexity of promoting healthy eating behaviours in adolescence, this study also showed that eating behaviour trajectories differed between girls and boys, and therefore calls for the need to develop gender-specific public health interventions that focus on multiple eating be- 
haviours. Further research is needed to identify factors that influence the co-development of eating behaviour trajectories.

Author Contributions: Conceptualisation, R.D., S.W., C.J., M.B.; formal statistical analysis, R.D.; visualisation, R.D., S.W., C.J., M.B.; writing—original draft preparation, R.D., S.W., C.J., M.B.; writingreview and editing, R.D., S.W., C.J., M.B.; supervision, M.B.; project administration, M.B.; funding acquisition, M.B. All authors have read and agreed to the published version of the manuscript.

Funding: The MATCH study is supported by the New Brunswick Health Research Foundation (20130729), the Social Sciences and Humanities Research Council (435-2016-0888), and Sport Canada through the joint Sport Participation Research Initiative (862-2010-0001 and 862-2014-0002). The funding organisations had no involvement in any stage of the study (design of the study, collection, analysis, interpretation of data or in writing the manuscript). RD holds a postdoctoral fellowship from Diabetes Action Canada.

Institutional Review Board Statement: The MATCH study was approved by the Comité d'Éthique de la Recherche du Centre Hospitalier de l'Université de Sherbrooke (11-025).

Informed Consent Statement: The informed assent and consent were obtained from all participants and their parents, respectively.

Data Availability Statement: The datasets generated during and/or analyzed during the current study are not publicly available to ensure confidentiality and that any secondary analyses correspond to the objectives of the research project but are available from the corresponding author on reasonable request.

Conflicts of Interest: The authors declare no conflict of interest.

\section{References}

1. Brown, J.E. Nutrition through the Life Cycle; Cengage Learning: Belmont, CA, USA, 2016.

2. Barr, S.I.; DiFrancesco, L.; Fulgoni, V.L. Breakfast consumption is positively associated with nutrient adequacy in Canadian children and adolescents. Br. J. Nutr. 2014, 112, 1373-1383. [CrossRef]

3. Han, E.; Powell, L.M. Consumption patterns of sugar-sweetened beverages in the United States. J. Acad. Nutr. Diet. 2013, 113, 43-53. [CrossRef] [PubMed]

4. $\quad$ Niemeier, H.M.; Raynor, H.A.; Lloyd-Richardson, E.E.; Rogers, M.L.; Wing, R.R. Fast food consumption and breakfast skipping: Predictors of weight gain from adolescence to adulthood in a nationally representative sample. J. Adolesc. Health 2006, 39, 842-849. [CrossRef] [PubMed]

5. Al Ani, M.F.; Al Subhi, L.K.; Bose, S. Consumption of fruits and vegetables among adolescents: A multi-national comparison of eleven countries in the Eastern Mediterranean Region. Br. J. Nutr. 2016, 115, 1092-1099. [CrossRef] [PubMed]

6. Chen, C.Y.; Hsiao, Y.C. Dual trajectories of breakfast eating and fruit and vegetable intake over a 5-year follow-up period among economically disadvantaged children: Gender differences. Appetite 2018, 121, 41-49. [CrossRef] [PubMed]

7. Lazzeri, G.; Pammolli, A.; Azzolini, E.; Simi, R.; Meoni, V.; de Wet, D.R.; Giacchi, M.V. Association between fruits and vegetables intake and frequency of breakfast and snacks consumption: a cross-sectional study. Nutr. J. 2013, 12, 123. [CrossRef] [PubMed]

8. Pedersen, T.P.; Meilstrup, C.; Holstein, B.E.; Rasmussen, M. Fruit and vegetable intake is associated with frequency of breakfast, lunch and evening meal: Cross-sectional study of 11-, 13-, and 15-year-olds. Int. J. Behav. Nutr. Phys. Act. 2012, 9, 9. [CrossRef]

9. Tambalis, K.D.; Panagiotakos, D.B.; Psarra, G.; Sidossis, L.S. Association between fast-food consumption and lifestyle characteristics in Greek children and adolescents; results from the EYZHN (National Action for Children's Health) programme. Public Health Nutr. 2018, 21, 3386-3394. [CrossRef]

10. Powell, L.M.; Nguyen, B.T. Fast-food and full-service restaurant consumption among children and adolescents: Effect on energy, beverage, and nutrient intake. JAMA Pediatr. 2013, 167, 14-20. [CrossRef]

11. Ranjit, N.; Evans, M.H.; Byrd-Williams, C.; Evans, A.E.; Hoelscher, D.M. Dietary and activity correlates of sugar-sweetened beverage consumption among adolescents. Pediatrics 2010, 126, e754-e761. [CrossRef]

12. Nagin, D.S. Group-Based Modeling of Development; Harvard University Press: Cambridge, MA, USA, 2005.

13. Cao, Y.; Xu, X.; Shi, Z. Trajectories of Dietary Patterns, Sleep Duration, and Body Mass Index in China: A Population-Based Longitudinal Study from China Nutrition and Health Survey, 1991-2009. Nutrients 2020, 12, 2245. [CrossRef] [PubMed]

14. Gao, M.; Wang, F.; Shen, Y.; Zhu, X.; Zhang, X.; Sun, X. Trajectories of Mediterranean Diet Adherence and Risk of Hypertension in China: Results from the CHNS Study, 1997-2011. Nutrients 2018, 10, 2014. [CrossRef] [PubMed]

15. Belanger, M.; Caissie, I.; Beauchamp, J.; O’Loughlin, J.; Sabiston, C.; Mancuso, M. Monitoring activities of teenagers to comprehend their habits: Study protocol for a mixed-methods cohort study. BMC Public Health 2013, 13, 649. [CrossRef] [PubMed]

16. O'Neil, C.E.; Byrd-Bredbenner, C.; Hayes, D.; Jana, L.; Klinger, S.E.; Stephenson-Martin, S. The role of breakfast in health: Definition and criteria for a quality breakfast. J. Acad. Nutr. Diet. 2014, 114, S8-S26. [CrossRef] [PubMed] 
17. Eaton, D.K.; Olsen, E.O.; Brener, N.D.; Scanlon, K.S.; Kim, S.A.; Demissie, Z.; Yaroch, A.L. A comparison of fruit and vegetable intake estimates from three survey question sets to estimates from 24-hour dietary recall interviews. J. Acad. Nutr. Diet. 2013, 113, 1165-1174. [CrossRef]

18. O'Malley Olsen, E.; Eaton, D.K.; Park, S.; Brener, N.D.; Blanck, H.M. Comparing methods for assessing beverage intake among high school students. Am. J. Health Behav. 2014, 38, 114-123. [CrossRef] [PubMed]

19. Brener, N.D.; Kann, L.; Shanklin, S.; Kinchen, S.; Eaton, D.K.; Hawkins, J.; Flint, K.H. Methodology of the Youth Risk Behavior Surveillance System-2013. MMWR Recomm. Rep. 2013, 62, 1-20. [PubMed]

20. Machado, J.A.; Silva, J.S. Quantiles via moments. J. Econ. 2019, 213, 145-173. [CrossRef]

21. StataCorp LP. Stata Multilevel Mixed-Effects Reference Manual; StataCorp LP: College Station, TX, USA, 2013.

22. Nagin, D.S.; Jones, B.L.; Passos, V.L.; Tremblay, R.E. Group-based multi-trajectory modeling. Stat. Methods Med. Res. 2018, 27, 2015-2023. [CrossRef] [PubMed]

23. Van der Nest, G.; Lima Passos, V.; Candel, M.J.J.M.; van Breukelen, G.J.P. An overview of mixture modelling for latent evolutions in longitudinal data: Modelling approaches, fit statistics and software. Adv. Life Course Res. 2020, 43, 100323. [CrossRef]

24. Jones, B.L.; Nagin, D.S. A note on a Stata plugin for estimating group-based trajectory models. Soc. Methods Res. 2013, 42, 608-613. [CrossRef]

25. Elmer, J.; Jones, B.L.; Nagin, D.S. Using the Beta distribution in group-based trajectory models. BMC Med. Res. Methodol. 2018, 18, 152. [CrossRef]

26. Arganini, C.; Saba, A.; Comitato, R.; Virgili, F.; Turrini, A. Gender differences in food choice and dietary intake in modern western societies. Public Health Soc. Behav. Health 2012, 4, 83-102.

27. Godin, K.M.; Patte, K.A.; Leatherdale, S.T. Examining predictors of breakfast skipping and breakfast program use among secondary school students in the COMPASS Study. J. Sch. Health 2018, 88, 150-158. [CrossRef] [PubMed]

28. Aljuraiban, G.S.; Chan, Q.; Oude Griep, L.M.; Brown, I.J.; Daviglus, M.L.; Stamler, J.; Van Horn, L.; Elliott, P.; Frost, G.S. The impact of eating frequency and time of intake on nutrient quality and Body Mass Index: The INTERMAP Study, a Population-Based Study. J. Acad. Nutr. Diet. 2015, 115, 528-536.e1. [CrossRef]

29. Cayres, S.U.; Júnior, I.F.; Barbosa, M.F.; Christofaro, D.G.; Fernandes, R.A. Breakfast frequency, adiposity, and cardiovascular risk factors as markers in adolescents. Cardiol. Young 2016, 26, 244-249. [CrossRef] [PubMed]

30. Gwin, J.A.; Leidy, H.J. A Review of the Evidence Surrounding the Effects of Breakfast Consumption on Mechanisms of Weight Management. Adv. Nutr. 2018, 9, 717-725. [CrossRef] [PubMed]

31. Nederkoorn, C.; Guerrieri, R.; Havermans, R.C.; Roefs, A.; Jansen, A. The interactive effect of hunger and impulsivity on food intake and purchase in a virtual supermarket. Int. J. Obes. 2009, 33, 905-912. [CrossRef]

32. Hall, K.D.; Ayuketah, A.; Brychta, R.; Cai, H.; Cassimatis, T.; Chen, K.Y.; Chung, S.T.; Costa, E.; Courville, A.; Darcey, V.; et al. Ultra-Processed Diets Cause Excess Calorie Intake and Weight Gain: An Inpatient Randomized Controlled Trial of Ad Libitum Food Intake. Cell Metab. 2019, 30, 226. [CrossRef]

33. Forkert, E.C.O.; Moraes, A.C.F.; Carvalho, H.B.; Manios, Y.; Widhalm, K.; González-Gross, M.; Gutierrez, A.; Kafatos, A.; Censi, L.; De Henauw, S.; et al. Skipping breakfast is associated with adiposity markers especially when sleep time is adequate in adolescents. Sci. Rep. 2019, 9, 6380. [CrossRef] [PubMed]

34. Statistics Canada. Health Fact Sheets: Fruit and Vegetable Consumption. 2017. Available online: https://www150.statcan.gc.ca/ n1/pub/82-625-x/2019001/article/00004-eng.htm (accessed on 30 March 2021).

35. Garriguet, D.; Bushnik, T.; Colley, R. Parent-Child Association in Physical Activity and Sedentary Behaviour. Health. Rep. 2017, 28,3-11. [PubMed]

36. WHO. Growing Up Unequal: Gender and Socioeconomic Differences in Young People's Health and Well-Being; World Health Organization: Geneva, Switzerland, 2016; ISBN 9289051361.

37. Polsky, J.Y.; Garriguet, D. Change in vegetable and fruit consumption in Canada between 2004 and 2015. Health Rep. 2020, 31, 3-12. [CrossRef]

38. Jones, A.C.; Kirkpatrick, S.I.; Hammond, D. Beverage consumption and energy intake among Canadians: Analyses of 2004 and 2015 national dietary intake data. Nutr. J. 2019, 18, 60. [CrossRef] [PubMed]

39. Langlois, K.; Garriguet, D.; Gonzalez, A.; Sinclair, S.; Colapinto, C.K. Change in total sugars consumption among Canadian children and adults. Health Rep. 2019, 30, 10-19. [PubMed]

40. WHO. Guideline: Sugars Intake for Adults and Children; World Health Organization: Geneva, Switzerland, 2015.

41. Singh, G.M.; Micha, R.; Khatibzadeh, S.; Lim, S.; Ezzati, M.; Mozaffarian, D. Estimated Global, Regional, and National Disease Burdens Related to Sugar-Sweetened Beverage Consumption in 2010. Circulation 2015, 132, 639-666. [CrossRef]

42. Todd, A.S.; Street, S.J.; Ziviani, J.; Byrne, N.M.; Hills, A.P. Overweight and obese adolescent girls: the importance of promoting sensible eating and activity behaviors from the start of the adolescent period. Int. J. Environ. Res. Public Health 2015, 12, 2306-2329. [CrossRef]

43. Patte, K.A.; Leatherdale, S.T. A cross-sectional analysis examining the association between dieting behaviours and alcohol use among secondary school students in the COMPASS study. J. Public Health 2017, 39, 321-329. [CrossRef]

44. Tannenbaum, C.; Greaves, L.; Graham, I.D. Why sex and gender matter in implementation research. BMC Med. Res. Methodol. 2016, 16, 145. [CrossRef] 
45. González-Gil, E.M.; Martínez-Olivan, B.; Widhalm, K.; Lambrinou, C.P.; de Henauw, S.; Gottrand, F.; Kafatos, A.; Beghin, L.; Molnar, D.; Kersting, M. Healthy eating determinants and dietary patterns in European adolescents: the HELENA study. Child Adolesc. Obes. 2019, 2, 18-39. [CrossRef]

46. Movassagh, E.Z.; Baxter-Jones, A.D.G.; Kontulainen, S.; Whiting, S.J.; Vatanparast, H. Tracking Dietary Patterns over 20 Years from Childhood through Adolescence into Young Adulthood: The Saskatchewan Pediatric Bone Mineral Accrual Study. Nutrients 2017, 9, 990. [CrossRef]

47. Bandini, L.G.; Schoeller, D.A.; Cyr, H.N.; Dietz, W.H. Validity of reported energy intake in obese and nonobese adolescents. Am. J. Clin. Nutr. 1990, 52, 421-425. [CrossRef] [PubMed] 